Başvuru Tarihi: 18.11.2016 Received Date: 18.11.2016

Yayına Kabul Tarihi: 11.01.2017 Accepted Date: 11.01.2017

Yayınlanma Tarihi: 30.01.2017 Published Date: 30.01.2017

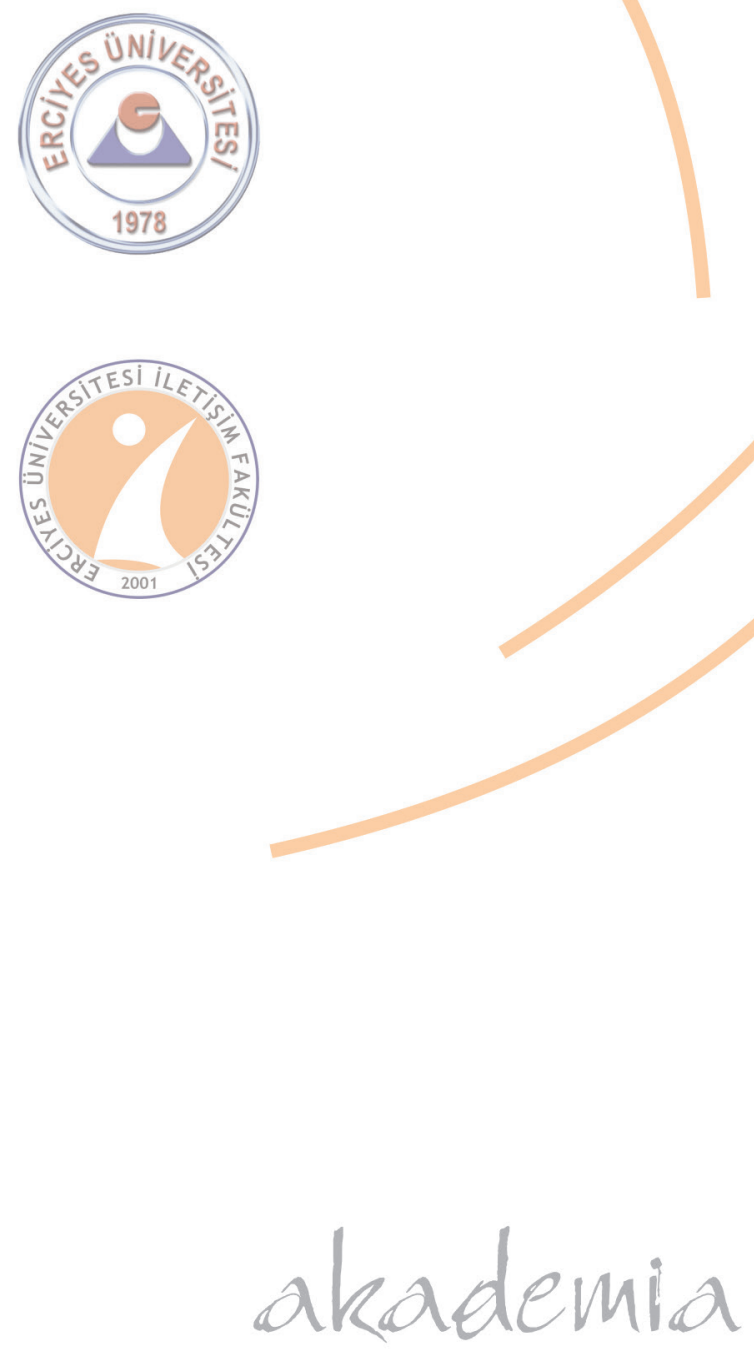


ISSN:1308-3198

Erciyes İletişim Dergisi "akademia" 2017

Cilt (Volume): 5, Sayı (Number): 1, (132-146)
Sibel Fügan VAROL (Yrd. Doç. Dr.)

Haliç Üniversitesi İşletme Fakültesi sibelvarol@halic.edu.tr

Neşe Kars TAYANÇ (Prof. Dr.)

İstanbul Üniversitesi İletişim Fakültesi nesekars@istanbul.edu.tr

\section{POPÜLER ARAMALAR, POPÜLER KÜLTÜR VE KÜLTÜREL KÜRESELLEŞME}

\section{$\ddot{\mathrm{O} z}$}

Bu çalışmada, arama motoru Google'da 2001-2015 yılları arasında en sık aranan anahtar sözcükler tespit edilerek son 15 yıllık süre içinde küresel düzeyde egemen durumdaki popüler eğilimler sorgulanmıştır. Sorgulama, Google Trends sitesindeki "Evrensel" kategorisinde yer alan veriler kullanılarak yapılmış, kültürel küreselleşmenin Türkiye'deki etkilerinin küresel sonuçlarla farkl11ık gösterip göstermediğini anlamak için "Türkiye" kategorisindeki veriler temelinde de benzer bir çalışma gerçekleştirilmiştir. Analiz sonucunda, başta ABD olmak üzere Batılı ülkelerde egemen popüler kültür öğelerinin internet erişimine sahip dünya nüfusunu etkisi altına almış olduğu, dolayısıyla küresel düzeyde hâkim popüler kültürün dünya ülkelerinin çeşitliliğini yansıtan bir mozaik sunmaktan ziyade homojenleşme eğilimi gösterdiği ve araştırma süresinin başlangıç ve bitiş yılları (2001 ve 2015) arasında bu durumda Batılı ülkeler lehine küçük de olsa $(\mathrm{p}=1.80)$ bir farklılaşma yaşandığı tespit edilmiştir. Çalışmanın ortaya koyduğu bir diğer tespit ise, Türkiye'de şu anda Batı merkezli homojen bir kültürden söz edilemeyeceği, yerel öğelerin popüler kültür eğilimlerinde büyük bir ağırlık taşıdığı, ancak yerel öğelerden arındırılmış sonuçlarda ağırlıklı olarak ABD merkezli kültürel öğelerin yer aldığı şeklindedir.

Anahtar Kelimeler: Küreselleşme, Popüler Kültür, Google Trends, Kültürel Homojenleşme, Kültürel Melezleşme.

\section{POPULAR SEARCHES, POPULAR CULTURE AND CULTURAL GLOBALIZATION}

\section{Abstract}

This article attempts to explore the global popular trends in a 15-year period from 2001 to 2015, examining the key words entered into Google as provided in the website Google Trends. The analysis was made using the search queries in the category "Universal" and then, it was repeated in the category "Turkey" to compare the results between them. The analysis has revealed that the popular culture trends in the Western countries, notably the USA, currently exercise a deep influence over the people of all countries with internet access, which means that the global popular culture does not show a mosaic reflecting the diversity of the different countries in the world, but implies a homogenisation tendency instead, and that there is a small variation $(\mathrm{p}=1.80)$ in favour of the Western countries in this tendency between the initial and last years of the period covered by the analysis (2001 and 2015). Another result of the analysis is that one may not assert the dominance of a Western-oriented homogenous culture in Turkey at present because of the predominance of the local cultural items although the analysis results free from local effects reveals that the USA originated cultural items are also dominant in Turkey.

Keywords: Globalization, Popular Culture, Google Trends, Cultural Homogenisation, Cultural Hybridisation. 


\section{Giriş}

Küreselleşmeye ilişkin tartı̧̧maların 1960'lı yıllarda Kanadalı iletişim bilimci Marshall McLuhan'ın “küresel köy” metaforuyla başladığı söylenebilir. McLuhan, "küreselköy” kavramıyla elektronik iletişimin yaygınlaşmasıyla birlikte dünyanın giderek küresel bir köye dönüştügünü anlatmak istemiştir. McLuhan'ın tespitini doğrularcasına, 20. yüzyılın sonları ülkelerarası sınırların önemini azaltan birçok gelişmeye sahne olmuştur. Bu dönemde ortaya çıkan uydu yayıncılı̆̆ 1 sayesinde, aynı televizyon programları dünyanın farklı yerlerinden izlenebilmeye başlanmış, yine aynı dönemde kullanıma giren internet, iletişimde ve bilgi paylaşımında zaman ve mekân sınırlarını ortadan kaldırmıştır. Özellikle internet sayesinde, uluslararası iletişim eskisinden çok daha kolay hale gelmiştir. Artık insanlar ülkelerinden, hatta evlerinden hiç ayrılmadan dünyanın birçok yerinden arkadaș edinebilmekte, deneyimlerini paylaşabilmekte, yazılı, görüntülü veya sesli olarak iletişim kurabilmektedir. Ulaşım teknolojilerinde yaşanan gelişmelerin yolculuk sürelerini kısaltması da ülkeler ve kıtalar arasındaki insan ve eşya dolaşımını artırmıştır. Tüm bu gelişmelerle birlikte girilen 21. yüzyılda ise, ülkeler arasındaki coğrafi sınırların önemi azalmış ve dünya, bir ucundan diğerine kolayca ulaşlabilen küresel bir köy haline gelmiştir.

Anthony Giddens (1990, 64), küreselleşmeyi, “dünya çapındaki toplumsal ilişkilerin, çok uzaklardaki olayların ve yerel oluşumların birbirini biçimlendirdiği ve uzak yerleşimlerin birbirine bağlandığı bir şekilde yoğunlaşması" olarak tanımlamıştır. Uzak yerleşimleri birbirine bağlayan güç ise medya ve iletişim teknolojileridir. Küreselleşme sürecinde kritik bir role sahip olan medya, bir yandan dünyayı bir "küresel köy" haline getirirken, bir yandan kendisi de küreselleşmiş ve şirket birleşmeleri sonucunda sayıları azalıp güçleri artan medya şirketlerinin faaliyet alanı ve etki gücü bütün dünyaya yayılmıştır.

Medyanın bilinç şekillendirmedeki etkin rolü ve kültürel etkileri uzun yıllardır önemli bir kayg1 ve tartışma konusu olmuştur. Küreselleşme sürecinin medya alanında da yaşanmasıyla birlikte, izleyicilerin farklı ülkelerde üretilen medya içeriklerine maruz kalmasının getirdiği sonuçlar da bu kaygı ve tartışmaların önemli bir parçasını oluşturmuştur. Günümüzde medyanın kültürün en önemli belirleyicilerinden biri haline gelmiş olması, medyadaki küreselleşmenin kültürel çeşitliliğe zarar vereceği yönünde kaygıların doğmasına neden olmuştur. Bu kaygıların ulaştı̆ğ nokta ise "küresel bir kültürün" bulunup bulunmadığı ve bu kültürün gerçekten de kozmopolit ve milliyetsiz olup olmadı $\breve{g} 1$ şeklindedir.

$\mathrm{Bu}$ çalışmanın çıkış noktasını da benzer sorular oluşturmaktadır. Küreselleşmenin farklı kültürlerin karşılaștığı, kozmopolit ve melez bir küresel kültüre mi yol açtığı, yoksa başta ABD olmak üzere Batılı ülkelerin kültürünü dünya üzerinde hâkim kılmaya çalıșan, kültürel çeșitlilik aleyhinde bir seyir mi izlediği sorusu bu makalenin çıkış noktasını oluşturmuştur. Makalenin soruya yanıt ararken mercek altına aldığı alan ise popüler kültür olmuştur. Zira bir dönemin "en gözde" ve "en beğenilen" unsurlarından oluşan popüler kültürdeki mevcut eğilimlerin tespit edilmesi, belli bir dönemin kültürel haritasının çıkarılmasına katkıda bulunacaktır. Sosyal bilimlerin en yoğun tartışılan konularından biri olan küreselleşmenin kültürel etkilerine ilişkin güncel veriler ise konuya ilişkin kuramsal birikimin deneysel bulgularla sınanması ve güncellenmesi açısından önem taşımaktadır.

\section{Popüler Kültürr}

Sosyal bilimlerin temel kavramlarından biri olan kültür, "bir toplumun paylaş1lan inanç, norm, değer, ritüel, dil, tarih, bilgi ve toplumsal karakterinin toplamı" (Bruce ve Yearley, 2006, 58) olarak tanımlanmaktadır. Gordon Marshall'a $(2005,442)$ göre, sosyal bilimlerde kültür, insan toplumunda biyolojik olarak değil, toplumsal araçlarla aktarllıp iletilen her şeyi anlatmaktadır. Ancak toplumsal yapı karmaşıklaşıp toplumdaki kültürel farklılaşmalar arttıkça, kültür kavramıyla anlatılan şeyin ne olduğu da zaman içinde değişmiş ve çeşitlenmiş, Marshall'ın 'insan toplumunun sembolik ve öğrenilmiş yönlerini anlatan genel bir terim" olduğunu söylediği kültür kavramı da bu değişim ve çeşitliliği anlatmaya yetmez olmuştur. Bunun sonucunda, farklı kültürel oluşumlar arasındaki ayrımı göstermek üzere, kültür kavramına farklı ekler getirilerek "halk kültürü”, “yüksek kültür”, "alt kültürr", "karşı kültür”, "etnik kültür” gibi yeni kavramlar oluşturulmaya başlanmıştır. 
Kültürel farklılaşmayı ve çeşitliliği anlatmak üzere kullanılan terimlerden biri de popüler kültürdür. Popüler kültür kavramını tanımlayıp özelliklerini açıklayan birçok yaklaşım bulunmaktadır. Bu yaklaşımların çeşitliliği, sosyal bilimlerdeki birçok diğer kavram gibi popüler kültür kavramının da çok anlamlılıktan doğan bir muğlaklıkla kullanılmasına yol açmıştır. Bu muğlaklığ Storey'den (2009) gelmiştir. Storey, popüler kültür kavramının sosyal bilimlerde altı farklı şekilde kullanıldığını ileri sürmüştür. Storey'in, ortak noktalarının popüler kültürün sanayileşme ve kentleşme sonrasında ortaya çıkan kültürel bir biçimlenme olduğunu kabul etmeleri olduğunu söylediği bu tanımlar aşağıda açıklanmıştır:

Storey'e $(2009,5)$ göre, popüler kültürün tanımlanma şekillerinden ilki geniş kesimlerin beğendiği kültür şeklindedir. Zaten popüler terimi de, "halka ait" anlamına gelen Latince popularis sözcügünden türetilmiştir. Ancak, popüler kavramı başlangıçta bütün halkı oluşturan veya onun adına yürütülen politik bir sistemle ilişkilendirilerek kullanılmış, "geniş kesimlerce beğenilen ve sevilen" şeklindeki bugünkü anlamını daha sonradan kazanmıştır (Williams, 1983, 236). Popüler kavramının anlamından yola çıkarak, popüler kültür de "geniş halk kesimlerinin beğendiği ve benimsediği kültür" ş̧eklinde tanımlanabilir. Her dönemde toplumun geniş kesimlerinin beğenip benimsediği bir kültürün var olması nedeniyle, bu tanım, popüler kültürün insanlık tarihi kadar eski olduğunu imlemektedir. Ancak "popüler kültür" kavramı için böyle bir genellemeyle yetinilmesi, bu konuda uzun yıllardır süregelen tartışmaların göz ardı edilmesi anlamına gelecektir. Özellikle popüler kültürün "ticari” bir nitelik taşıdığına ilişkin yaygın görüş nedeniyle, ticari amaçlı olmayan, fakat geniş kesimlerin beğenisini kazanmış kültürel oluşumların da popüler kültür sayılıp sayılmayacağı sorusunun yanıtlanması gerekmektedir.

Storey'in sınıflandırmasında yer alan ikinci popüler kültür tanımı, yüksek sanatın dışında kalan kültürel biçimler şeklindedir. Bu tanım, Storey’e göre, popüler kültürün kitlesel olarak üretilen ticari amaçlı bir kültür olduğu, yüksek kültürün ise bireysel bir yaratma işleminden doğduğu, dolayısıyla, yüksek kültürün ahlaki ve estetik bir değerinin bulunduğu iddiasına dayanır $(2009,6)$. Aslında popüler kültür kavramı yüksek kültürden farklı olanı vurgulamak üzere kullanılmaktadır. Popüler kültür-yüksek kültür ayrımında, popüler kültür "alt" sınıfların yaşam tarzı ve zevkleriyle ilişkilendirilirken, sofistike ve estetik kültürel ürünler yüksek kültüre dâhil edilmektedir. Bu bağlamda, popüler kültür, Veysel Batmaz'ın ifadesiyle söylenirse (aktaran Yaylagül ve Korkmaz, 2008, 130), "üstte seçkin kültürle altta halk kültürünün arasında yer alan gündelik yaşamın sözlü ve görsel olarak yeniden üretilmesini sağlayan bir kitle kültürü türüdür.” Yüksek kültür ise, Diana Kendall'ın $(2011,62)$ tanımladığı haliyle, bu kültürel türü beğenmesi için gerektiği düşünülen bilgi, para ve zamana sahip olan ve esas olarak üst-orta ve üst sınıftan elitlerin takip ettiği klasik müzik, opera, bale, tiyatro ve diğer aktivitelerden oluşan kültürü ifade etmektedir.

Üçüncü tanıma göre, popüler kültür kitle kültürüdür. Büyük ölçüde ikinci tanımdaki iddialara dayanan bu yaklaşıma göre, popüler kültür ticari bir kültürdür. Kitlesel tüketim için kitlesel olarak üretilir. İzleyicileri, farklılaşmamış tüketicilerden oluşan bir kitledir. Formüllere dayanır. Manipülatiftir. Beyni uyuşturan bir pasiflikle, uyuşmuş beyinler tarafından tüketilir (Storey, 2009, 8). Bu özellikler popüler kültürle özdeşleştiren kitle kültürünü anlatmaktadır. Kitle kültürü de Levent Yaylagül ve Nilüfer Korkmaz'ın ifadesiyle, kitle iletişim araçlarıyla topluma yayılan düşünce, davranış, anlatı ya da temsillerin tümü şeklinde tanımlanmaktadır $(2008,127)$. Kitle kültürü düşüncesi 1920'li ve 1930'lu yıllarda açık bir şekilde tartışılmaya başlanmıştır. Dominic Strinati'ye göre, bu yıllar, popüler kültür araştırmaları ve değerlendirmeleri için önemli bir dönüm noktası olmuştur. Sinema ve radyonun kitlelerin kullanımına sunulması, kültürün kitlesel üretim ve tüketimi, bazı batı toplumlarında faşizmin yükselmeye başlaması ve liberal demokrasilerin olgunlaşması popüler kültürle ilgili tartışma gündemini belirleyen unsurlar olmuştur $(2004,3)$. Aslında kitle kültürünün ortaya çıkışı bir önceki yüzyıla uzanmaktadır. Dwight MacDonald $(1963,59)$, bu durumu, demokrasinin ve popüler eğitimin 1800'lü yılların başlarından itibaren üst sınıfın önceki kültür tekelini kırması ve ticari işletmelerin yeni uyanmış kitlelerin kültürel taleplerine yönelik kârlı bir pazar bulmasıyla açıklamıştır. Yine aynı dönemde 
yaşanan teknolojik gelişmeler ise kitap, dergi, resim, müzik gibi kültürel ürünlerin ucuza üretimini mümkün kılmış, dönemin modern teknolojisi de kitlesel üretim ve dağıtıma uyarlanmış olan ve dönemin yeni medyası niteliğindeki sinema ve televizyonu yaratmıştır.

Storey'in sınıflandırmasındaki dördüncü tanım, popüler kültürün halktan doğduğu iddiasına dayanmaktadır. Popüler kültürün halka yukarıdan empoze edildiğini iddia eden yaklaşımlara karşı çıkan bu tanıma göre, popüler kültür terimi yalnızca "halkın" otantik kültürünü göstermek üzere kullanılmalıdır. Bu, anlamıyla popüler kültür halk kültürü veya işçi sınıfı kültürüdür. Storey, bu tanımdaki iki soruna dikkat çekmiştir. Bunlardan biri, "halk" kategorisine kimlerin dâhil edileceğinin muğlak olması, ikincisi ise, popüler kültürün üretildiği kaynakların çoğunun "ticari" niteliğini göz ardı etmesidir $(2009,9)$. Gerçekten de, popüler kültürün "halk kültürü" olarak kabul edilmesinin oldukça problemli olduğu söylenebilir. Zira "halk kültürü", özellikle endüstri öncesi toplumlardaki geniş halk kesimlerinin gündelik kültürü anlamında kullanılmaktadır. Halk kültürü, Emre Gökalp'ın $(2009,104)$ tanımıyla söylenirse, bugün, kültürel olarak türdeş bir topluluk içinde genellikle anonim olarak üretilen ve nesilden nesle sözlü olarak aktarılan kültür anlamında kullanılmaktadır. Popüler kültür ise, John Fiske'in (1991, 208) ifadesiyle, halk kültürünün aksine, gelişmiş, sanayileşmiş toplumlar tarafindan üretilir; endüstri aracılığıyla üretilip dağıtılan metalardan oluşturulur. Kısa sürede siliniveren, oldukça kısa ömürlü bir kültürdür. Üreticilerinin dışındaki kesimlerce tüketilir.

Storey, popüler kültürün beşinci tanımının, büyük ölçüde İtalyan Marksist Antonio Gramsci'nin "hegemonya" kavramına dayandığını söylemiştir. Gramsci, hegemonya kavramıyla, egemen grupların yönetilenlerin rızasını kazanmak için kullandıkları entelektüel ve ahlaki bir liderlik sürecini anlatmak istemiştir. Bazı kültürel kuramcılar ise, hegemonya kavramını, popüler kültürün doğasını ve popüler kültür politikalarını açıklamak üzere kullanmıştır. Bu yaklaşımın savunucuları, popüler kültürün ne kitle kültürü teorisyenlerinin iddia ettiği gibi yukarıdan empoze edilmiş bir kültür ne de aşağıdan gelen, kendiliğinden muhalif nitelikte bir "halk" kültürü olmadığını, bağımlı grupların direnişiyle egemen grupların çıkarları lehine hareket eden "sisteme katma" güçleri arasındaki mücadele alanı olduğunu ileri sürmüştür (Storey, 2009, 10).

Altıncı tanım, son dönemlerdeki postmodernizm tartışmaları kapsamında yapılmıştır. Postmodern kültürün yüksek kültür ve popüler kültür ayrımını ortadan kaldırdığı önermesi bu yaklaşımın çıkış noktasını oluşturmaktadır. Bazı yazarlar için bu gelişme, kültürün keyfi ayrımları üzerine bina edilmiş seçkinciliğe son vermesi nedeniyle olumludur. Bazı yazarlara göreyse ticaretin kültür karşısındaki nihai zaferi olması nedeniyle umut kırıcı niteliktedir (Storey, 2009, 12).

Kendisine yüklenen farklı anlamlar nedeniyle, popüler kültür kavramı temelinde yürütülecek her çalışmanın kavrama yüklediği anlamı belirterek yola çıkması gerekmektedir. Geniş kitlelerin güncel kültürel beğenilerinin tespit edilmesini amaçlaması nedeniyle, bu çalışmada popüler kültür kavramı birinci tanımdaki gibi "geniş kitlelerin beğenisini kazanan kültürel unsurlar" anlamıyla kullanılmıştır.

\section{Kültürel Küreselleşme}

Kültürel küreselleşme, "dünyanın bir yerinde üretilen bilgi, mal ve imgelerin küresel dolaşıma girerek ulus, bölge ve bireyler arasındaki kültürel farklılıkları 'düzleştirme' eğiliminde olan süreç” (Heywood, 2011, 147) şeklinde tanımlanmaktadır. Kültürel küreselleşme olarak adlandırılan bu süreç medyanın küreselleşmesinden bağımsız düşünülemez. Medyanın küreselleşmesi ise, çok uluslu medya kuruluşlarının dünya çapındaki hâkimiyetinin artması şeklinde tanımlanabilir. Bu süreç, Ulla Carlsson'ın ifadesiyle, bilgi teknolojilerindeki hızlı yenilikler, medya ve iletişim sektörlerinde devlet müdahalesinin azalması ve medya sahipliğindeki tekelleşme eğilimi nedeniyle hızlı bir şekilde gerçekleşmiştir. Özellikle iletişim uyduları, sayısallaşma ve bilgisayar teknolojilerindeki ilerlemeler sayesinde televizyon programı, film, haber, oyun ve reklam gibi medya ürünlerine yönelik küresel pazar önemli ölçüde büyümüştür $(2002,8)$. Küresel medya pazarı büyürken, pazara hâkim medya şirketi sayısında azalma yaşanmış, büyük medya şirketleri arasında son birkaç on yıldır yaşanan birleşmeler az 
sayıda medya devinin ortaya çıkmasına yol açmıştır. Bunun sonucunda ise, günümüzde küresel medya sistemi, Time Warner, Disney, Bertelsman, Viacom, Tele-Communications INC, News Corporation, Sony, Seagram, General Electric ve Philips gibi az sayıda güçlü çok uluslu medya devinin egemenliği altına girmiştir (Kellner ve Pierce, 2007; Matos, 2012).

Medya şirketlerinin birkaç şirketin elinde yoğunlaşması ise çeşitliliği tehdit etmesi, gerçek rekabeti engellemesi, küçük oyuncuları piyasanın dışında tutması, dünyaya ilişkin geleneksel görüşlerin pekişmesine katkıda bulunması, muhalefeti ve kâr getirmeyen ya da kapitalist değerlere karşı çıktığı düşünülen içerikleri marjinalleştirmesi nedeniyle eleştirilmektedir (Matos, 2012). Dahası, az sayıdaki medya kuruluşunun dünyanın dört bir yanına bilgi, enformasyon ve eğlence olarak ulaşan medya içeriklerinin üretim ve dağıtımında önemli bir role sahip olması küreselleşmeyle medya arasındaki ilişkinin kültürel hegemonya, tek tipleşme ve bilinç yönetimi gibi çeşitli boyutlarda da sorgulanmasına neden olmuştur. Zira Graeme Burton'un (2005, 329) ifadesiyle, küresel ölçekte üretilip dağıtılan medya metinleri birer kültürel üründür ve kültürel pratikleri birbirine bağlamaktadır. Bu açıdan bakıldığında, küreselleşme yalnızca uluslararası politikalarla veya diğer medya emperyalizmi türleriyle değil, aynı zamanda toplumsal pratikler, toplumsal kurumlar ve insanların hayatıyla ilgili bir şeydir.

Manfred B. Steger $(2003,76)$ de, günümüzdeki kültürel akışın ağırlıklı olarak mesajlarını yaymada güçlü iletişim teknolojilerini kullanan küresel medya imparatorlukları tarafindan oluşturulup yönlendirildiğini söylemiştir. Bu dev şirketler, bütün dünyada insanların kimliklerini ve isteklerini şekillendirebilmektedir. Stig Hjarvard $(1999,71)$ ise, medyanın küreselleşmesinin ve az sayıdaki uluslararası dev medya şirketinin küresel medya pazarına hâkim olmasının, bu şirketlerin sahip olduğu güçlü teknolojik altyap1 ve finansal sermayeyle birleşerek "yeni bir medya düzeni” oluşturduğunu söylemiştir. Bu yeni medya düzen ise, Hjarvard'a göre, yerel kültürel tüketim kalıplarını etkilemekte ve bağımsız bir kültür üretimini zorlaştırarak yerel ve ulusal kültürlere yönelik bir tehdit oluşturmaktadır.

Steger ve Hjarvard'ın değindiği kaygılar kültürel küreselleşmenin kültürel homojenleşmeye yol açtığı yönündeki eleştirilerin de çıkış noktasını oluşturmaktadır. Kültürel homojenleşme, başta ABD olmak üzere Batılı ülkelerin politik, ekonomik, toplumsal ve kültürel değerlerinin dünya üzerinde egemen değerler haline geldiği iddiasına dayanmaktadır. Zira küresel medya devleri çok uluslu olmakla birlikte, ağırlıklı olarak Batılı, özellikle de ABD'li şirketlerdir (bkz. Tablo 1). Bu tablo, kültürel küreselleşmenin aslında Stuart Hall'ün $(1991,28,32)$ dediği gibi, "Amerikan yaşam tarzının küreselleşmesi”" olduğu savını güçlendirmektedir. Hall'e göre, küreselle yerel olanın birlikte var olduğu yeni küreselleşme türü küresel kitle kültürünü oluşturmaktadır. Küresel kitle kültürü ise Batı merkezlidir. İtici güçlerini Batının teknolojisi, teknik yoğunlaşma, sermayenin yoğunlaşması, Batı toplumlarındaki ileri emek yoğunlaşması ve Batı toplumlarının öykü ve hayalleri oluşturmaktadır.

Tablo 1: 2015 Yılı Verilerine Göre Dünyanın En Büyük 10 Medya Şirketi.

\begin{tabular}{|l|}
\hline Comcast (ABD) \\
\hline Walt Disney (ABD) \\
\hline Twenty-First Century Fox, Inc. (ABD) \\
\hline Time Warner (ABD) \\
\hline Time Warner Cable (ABD) \\
\hline Directtv (ABD) \\
\hline WPP (Ingiltere) \\
\hline CBS (ABD) \\
\hline Viacom (ABD) \\
\hline British Sky Broadcasting (Ingiltere) \\
\hline
\end{tabular}

Kaynak: www.forbes.com 
Hall'e paralel olarak George Ritzer de kültürel küreselleşmenin aslında Amerikan kültürünün küreselleşmesi olduğunu savunarak bu durumu "McDonaldlaştırma" şeklinde adlandırmıştır. Ritzer, "McDonaldlaştırma" kavramıyla, Amerikan tüketim kültürü ikonlarının, üretim sürecinin ve tüketim kalıplarının McDonald's fast food restoranlarında olduğu gibi franchising sistemiyle farklı ülkelere aktarıldığına işaret etmiştir. Franchising sistemi üzerinden, tüketim kültürü temelindeki yaşam tarzının yanı sıra, modern rasyonalizasyon süreçleri, modern üretim ve teslimat uygulamaları ve tek tip alışveriş ilişkileri yerleşip yayılmakta, kültürel farkl11ıklar dikkate alınmamaktadır (aktaran Kellner ve Pierce, 2007, 388).

Kültürel küreselleşmenin kültürel çeşitliliği giderek yok ettiğini ve kültürel homojenleşmeye yol açtığını ileri süren bu yaklaşım kültür emperyalizmi tezine dayanmaktadır. Liesbeth de Block ve David Buckingham'a $(2007,5)$ göre, bu yaklaşım dünyanın birincil süper gücü olarak doğrudan ABD'yi hedef göstermekte ve ABD medyasının kültürel homojenleşmenin güçlü araçları olduğunu ileri sürmektedir. Yine aynı yaklaşıma göre, ABD medyası yerel kültürleri aşındırmakta, tek bir ideolojiyi ve dünya görüşünü empoze etmektedir. Bu gelişme ise, kapitalist büyümenin kaçınılmaz bir sonucudur. ABD, hegemonyasını fiziksel işgalden ziyade, "Cocacolalaştırma" olarak da adlandırılan ideolojik ve kültürel egemenlik üzerinden sürdürmektedir.

Diğer taraftan, "kültürel homojenleşme" olarak ifade edilen bu yaklaşım kültürel küreselleşmeye ilişkin iki ana yaklaşımdan birini oluşturmaktadır. Philip Smith, 1980'li ve 1990'lı yıllarda, kötümser vurgulu bu düşünce şeklinin sorgulanmaya başlandığını ve ardından, küresel ve yerel olanın karmaşık karşıllklı etkileşimine vurgu yapan ikinci bir modelin ortaya çıktığını söylemiştir (2001, 231). Bu modele göre, küreselleşme dünyanın farklı noktalarındaki kültürlerin karşılaşmasını sağlamakta, özellikle yeni iletişim teknolojileri sayesinde dünyanın ücra köşelerindeki insanların dâhi kendilerini ifade etmesine imkân veren bir gelişme yaşanmaktadır. Dahası, de Block ve Buckingham'ın $(2007,5,6)$ dediği gibi, bu yaklaşımın savunucuları, "kültürel homojenleşme" savını izleyicilerin aktifliğini ve çeşitliliğini göz ardı ettiği, izleyicilere çocuk muamelesi yaptığı ve izleyicilerin sömürgeci ideolojilere direnecek güçlerinin olmadığını ima ettiği gerekçesiyle eleştirmektedir. Oysa ikinci yaklaşımın savunucularına göre, izleyici araştırmalarından elde edilen sonuçlar, küresel izleyicilerin ABD menșeli kültürel ürünlerde içkin Amerikan kültürünün değerlerini kendilerinin kültür ve altkültür aidiyetleri ışığında yorumladıklarını ortaya koymuştur. Kaldı ki kültürel malların akışı tek yönlü değildir. Küresel ticaret, ulus devletler ve yerel piyasalar arasındaki ilişkiler daha karmaşık ve çeşitlidir. Ekonomik güç de mutlaka ideolojik egemenlikle sonuçlanmayabilir.

Heywood $(2011,151)$, küreselleşmenin kültürel homojenleşmeye yol açtığına karşı çıkan yaklaşımın aşağıda açıklanan üç temel sava dayandığını söylemiştir:

Küresel melezleşme. Kültürel alışveriş yukarıdan aşağı veya tek yönlü bir süreç değildir. Aksine, küresel kültür pazarının ortaya çıkması sonucunda ekonomik ve politik açıdan güçlü olanlar da dâhil bütün toplumların çeşitliliği artmıştır. Örneğin bir yandan Coca-Cola, McDonalds ve MTV Batılı ülkelerden diğer ülkelerin kültürüne nüfuz ederken, gelişmiş ülkeler de Batılı olmayan ülkelerin dinlerinden, yiyeceklerinden (soya sosu, Hintlilerin köri baharatları, tortilla), ilaç ve tedavi uygulamalarından (akupunktur, yoga, Budist meditasyon), sporlarından (judo, karate, kick-boxing), vs. etkilenmiştir (Heywood, 2011, 151). Dolayısıyla, küreselleşme, homojenlik yerine aktif olarak kültürel çeşitlilik üretmektedir ve gerçekte yaşanan şey, küresel medya biçimlerinin yerli deneyimler ve geleneklerle birleşerek yeni "melezlik" biçimleri (örneğin hip-hop) doğurmasıdır (de Block ve Buckingham, 2007, 6).

Yerelin dönüşü. Küreselin kendini yerel şartlara uydurması veya yerel etkileri güçlendirmesi de küreselleşmeyi homojenleşme olarak kabul eden tezin yanlışlığını ortaya koymaktadır. Örneğin, gelişmekte olan ülkelerde, yabancı ülkelerin emtia ve pratikleri yerel şartlara ve ihtiyaçlara uyarlanmaktadır. Bollywood film endüstrisi ve Al-Jazeera televizyon ağ 1 bu tür yerelleşme ve uyarlama pratiklerine örnek olarak gösterilebilir. Yerel aktörlerin küresel seçenekler arasından belli unsurları seçerek değiş̧irme işlemini Ronald Robertson (1998, 151, 
173) "glokalleşme" (Türkçeye uyarlanmış haliyle "küyerelleşme") olarak tanımlamıştır. Yerel şartlara uyarlanmış küresel bir bakış açısını yansıtmak üzere Japon iş çevrelerinde türetilmiş olan glokalleşme terimi, Ritzer'in $(2011,159)$ işaret ettiği gibi, küresel ve yerel olanın farklı coğrafik bölgelerde özgün sonuçlar verecek şekilde iç içe girmesi olarak da ifade edilmektedir.

Kültürel kutuplaşma. Ekonomik ve kültürel küreselleşmenin yabanc1 ve tehditkâr değer ve pratikleri empoze ettiği durumda, bazen bir geri tepme yaşanmakta, bu ise homojenleşmeye değil, kutuplaşmaya yol açmaktadır. Bu durum Samuel Huntington'ın "medeniyetlerin çatışması" tezinde kendini göstermektedir. Bu teze göre, Soğuk Savaşın sona ermesinden itibaren, küresel politikaların Batılı niteliği sona ermiş, Batılı ve Batılı olmayan medeniyetler arasındaki etkileşim küresel politikanın merkezi haline gelmiştir. Bu nedenle, temel medeniyet çatışmaları ABD ve Çin ile Batı ve İslam arasında yaşanacaktır (Heywood, 2011, 151).

Kültürel küreselleşme konusunda yukarıda özetlenen bu iki yaklaşımdan yalnızca birinin doğru, diğerinin yanlış olduğunu söylemek mümkün değildir. Yine de aralarından birinin mevcut durumu diğerine nazaran daha gerçekçi bir şekilde yansıttığı söylenebilir. Bu makalenin tespit etmeye çalıştığı şey de, kültürel küreselleşmenin günümüzdeki yöneliminin "kültürel homojenleşme" ve "kültürel melezleşme" şeklinde özetlenebilecek bu iki yaklaşımdan hangisine daha yakın olduğudur. Gerçekten de, yerel ve geleneksel kültürler giderek kaybolurken onun yerini Amerikan kültürü mü almaktadır? Yoksa bugün yaşanan şey uzaktakinin yakındakiyle buluştuğu, kültürel çeşitliliği artıran, Batı ve Doğu'nun birbiriyle karıştığı küresel bir kültür müdür? Türkiye'deki mevcut popüler kültür eğilimleri dünyanın genelinden farklı bir seyir izlemekte midir? $\mathrm{Bu}$ soruların yanitına Google Trends (https://www.google.com/trends/) sitesinde yer alan veriler analiz edilerek ulaşılmaya çalışı1mıştır.

\section{Araștırmanın Yöntemi:}

$\mathrm{Bu}$ çalışmada, gerek dünyadaki gerekse Türkiye'deki popüler kültür eğilimlerinin homojenleşme yönünde mi yoksa melezleşme yönünde mi seyir izlediğini tespit etmek üzere doküman inceleme yöntemi kullanılmıştır. Araştırılan konulara ilişkin bilgi içeren yazılı materyallerin analizi şeklinde tarif edilebilecek doküman incelemesi, geleneksel olarak, tarihçiler, antropologlar ve dil bilimcilerin kullandığı bir yöntem olmakla birlikte, sosyolog ve psikologlar tarafından da kullanılarak önemli kuramların geliştirilmesine katkıda bulunmuştur (Yıldırım ve Şimşek, 2008, 167). Çalışmada, Google Trends sitesi geçmiş döneme ait verilerinin ulaşılabilir olması nedeniyle doküman olarak kabul edilmiştir.

Google Trends, Google aramalarında sözcük veya tümce sorgularının hangi coğrafyada, hangi dillerde ve ne sıklıkla arandığını istatistiksel olarak sunan bir sitedir (https://tr.wikipedia. org/wiki/Google_Trends). Bu sitedeki veriler dünyadaki ve Türkiye'deki popüler kültür eğilimlerini ortaya çıkarmak amacıyla içerik analizine tabi tutulmuştur. Klaus H. Krippendorff (2004, 18), içerik analizini metinlerden (ya da diğer anlamlı içeriklerden) kullanıldıkları bağlamda yinelenebilir ve geçerli çıkarsamalar yapmayı sağlayan bir araştırma tekniği olarak tanımlamıştır. İçerik analizinde yapılan işlem, birbirine benzeyen verileri belli kavram ve temalar çerçevesinde bir araya getirmek ve bunları okuyucunun anlayabileceği bir biçimde düzenleyerek yorumlamaktır (Yıldırım ve Şimşek, 2008, 227). Bu çalışma kapsamında da, Google Trends sitesinde yer alan arama sorgularının sınıflandırıldığı kategori ve başlıklar tespit edilmiş ve içerdikleri arama sorguları kodlanarak sayısal verilere ulaşılmıştır.

Çalışmanın evrenini Google Trends sitesinde arama sorgularının yer aldığı bütün kategori ve başlıklar oluşturmaktadır. Çalışmanın örnekleminin seçilmesinde ise küme örnekleme yöntemi kullanılmıştır. Küme örnekleme, çalışılması düşünülen evrende doğal olarak oluşmuş veya farklı amaçlarla yapay olarak oluşturulmuş, kendi içinde belli özellikler açısından benzerlik gösteren değişik grupların olması durumunda kullanılmaktadır (Yıldırım ve Şimşek, 2008, 105). Google Trends sitesinde yer alan Evrensel ve Türkiye kategorileri de çalışma evreninde doğal olarak oluşmuş ve kendi içinde benzerlik gösteren gruplar olmaları nedeniyle bu araştırmanın örneklemi olarak kabul edilmişlerdir. 
Google Trends sitesinde yer alan başlıklar altında yer alan arama sorguları çalışmanın analiz birimi olarak kabul edilmiştir. Kültürel küreselleşmenin dünyada ve Türkiye'de benzeşme şeklinde mi yoksa melezleşme şeklinde mi yaşandığını tespit etmek üzere, analiz birimine aşağıdaki araştırma soruları yöneltilmiştir:

A.S.1. Kültürel küreselleşme kültürel homojenleşmeye mi yoksa melezleşmeye mi yol açmaktadır?

A.S.2. Küresel kültür giderek Amerikan kültürüne mi benzemektedir?

A.S.3. Türkiye'de hâkim kültürel eğilimler dünya genelindeki kültürel küreselleşme eğiliminden farkl1l1k göstermekte midir?

Yukarıdaki araştırma sorularını yanıtlamak üzere, analiz birimi Tablo 2'de gösterilen kategori ve başlıklar temelinde incelenmiştir:

Tablo 2: İ̧̧erik Analizine Dâhil Edilen Kategori ve Başlıklar ${ }^{1}$

\begin{tabular}{|c|c|c|}
\hline Kategori & Başlık & $\begin{array}{l}\text { İncelenen } \\
\text { Dönem }\end{array}$ \\
\hline Evrensel & $\begin{array}{l}\text { Genel Aramalar, Haberler, Televizyon Programları, Kaybettiklerimiz, Kişiler, } \\
\text { Spor, Tüketici Elektronikleri, Eğlence, Filmler ve Müzik Sanatçıları }\end{array}$ & $\begin{array}{l}2001-2015 \\
\text { arası }\end{array}$ \\
\hline Türkiye & $\begin{array}{l}\text { Genel Aramalar, Haberler, Şarkıcılar, Şarkılar, Başlıklar, Şöhretler, Spor } \\
\text { Takımları, Filmler, Diziler, Seyahat İstikametleri, Televizyon Programları ve } \\
\text { Kişiler }\end{array}$ & $\begin{array}{l}2011-2015 \\
\text { arası }\end{array}$ \\
\hline
\end{tabular}

Analize dâhil edilen başlıkların seçiminde, ilişkili ülkelerin tespit edilebilmesi ve kitlelerin ilgi konularını yansıtması ölçütleri kullanılmıştır. Analiz kapsamında, öncelikle, Tablo 2'de belirtilen kategori ve başlıklar kapsamındaki arama sorguları bir kodlama sürecine tabi tutulmuştur. Kodlama, veriler arasında yer alan anlamlı bölümlere isim verilmesi sürecidir. $\mathrm{Bu}$ aşamada, verilerden çıkarılan kavramlara göre yapılan kodlama tekniği kullanılmıştır. Söz konusu teknikte, veriler taranarak araştırmacının amacı çerçevesinde önemli olan boyutlar saptanmaya çalışılmakta, ortaya çıkan anlama göre, belirli kodlar üretilmekte ya da doğrudan verilerden yola çıkarak kodlar oluşturulmaktadır (Yıldırım ve Şimşek, 2008: 227-232). Bu doğrultuda, araştırma örnekleminde yer alan arama sorguları kodlanarak ilişkili oldukları ülkeler tespit edilmiş, böylece, arama sorgularından oluşan veri kümesi ülke kümesine dönüştürülmüştür. Kodlamayla elde edilen veriler Batılı ülke/Batılı olmayan ülke ayrımına tabi tutularak, arama sorgularıyla ilişkili ülkelerin yer alma sıklıkları (n) ve yüzdeleri (\%) hesaplanmıştır. Batılı ülke-Batılı olmayan ülke ayrımının kesin hatlarıyla yapılması mümkün olmamakla birlikte, bu çalışmada, "medeniyetler çatışması" tezinin sahibi Huntington'ın 1990 sonrası için öngördügüü Batılı ve Batılı olmayan ülkeler haritasında ( 1996, 26-7) önerilen sınıflandırma esas alınmıştır.

Google Trends sitesinde yer alan başlıkların ve her başlıkta yer alan sorgu sayısının değişkenlik göstermesi nedeniyle, kodlama sırasında belli kurallar benimsenerek araştırma boyunca uygulanmış, böylece araştırmanın kendi içinde tutarlı ve tekrarlanabilir olması sağlanmaya çalışılmıştır. Araştırmada benimsenen kurallar aşağıda sıralanmıştır:

a. Arama sorgularının ilişkili olduğu ülkeler belirlenirken şu ölçütler esas alınmıştır;

- Film: Yapımcı şirketin merkezinin bulunduğu ülke

- Televizyon programı: Yapımcı şirketin merkezinin bulunduğu ülke

- Video oyunları: Oyunu geliştiren şirketin merkezinin bulunduğu ülke

- Ürün/hizmet markaları: Üretici/hizmet sağlayıcı merkezinin bulunduğu ülke

- Kitaplar: Yayınevinin bulunduğu ülke

- Kişiler: Doğduğu ülke

${ }^{1}$ Evrensel ve Türkiye kategorilerinde incelenen dönemler ve başlıklar arasındaki farklılaşma Google Trends sitesinde yer alan verilerdeki farklılaşmadan kaynaklanmaktadır. 
- Haberler: Olayın geçtiği ülke

- Şarkılar: Piyasaya ilk sürüldüğü ülke.

b. Film Fragmanları Filmler başlığına, Sporcular ve Spor Etkinlikleri Spor başlığına, Tatil Yerleri Seyahat İstikametleri başlı̆̆ına dâhil edilmiştir.

c. Tek bir arama sorgusunun birden fazla ülkeyle bağlantılı olması nedeniyle, bazı başlıklarda (özellikle ortak yapım filmler durumunda Film başlığında) o başlık altındaki toplam arama sorgusu sayısıyla bağlantılı ülke sayısının eşit olmadığı durumlar mevcuttur.

d. Kişiler başlığının bulunmadığ 1 yıllarda, Kadın ve Erkek başlıkları varsa, bu iki başlık altındaki ilk beş kişi dikkate alınarak Kişiler başlığı oluşturulmuştur (bu kural yalnızca 2004, 2002 ve 2001 yıllarında uygulanabilmiştir).

e. Bir sorgunun birden fazla ülkeyle ilişkili olduğu durumlarda, ülke sayısı üçten fazlaysa o sorgu "Uluslararası" grubuna dâhil edilmiş, üç veya daha az ise bu ülkelerin tümü birden dikkate alınmış, her biri ayrı birer ülkeymiş gibi değerlendirilmiştir.

f. Youtube, Twitter gibi izler kitlenin katılımına imkân veren siteler "Genel" grubuna dâhil edilmiştir.

g. Araştırmaya dâhil edilen başlıklarla ilişkili olduğu durumda Popülerliği Artan ve En Hızlı Artan başlıkları altındaki veriler kullanılmış, Popülerliği Azalan Veriler dikkate alınmamıştır.

h. Her başlık altında çoğunlukla 10 sonuç verilmiş olup, 10'dan fazla sonuç bulunduğu durumlarda ilk 10 sorgu, daha az sonuç bulunduğunda ise mevcut sorguların tümü dikkate alınmıştır.

1. Uluslararası ve Genel grubunda kodlanan sonuçlar Batıl1-Batılı olmayan ülke sınıflandırması yaparken değerlendirmeye katılmamış, ancak toplam ülke sonucu ve bir ülkenin toplam ülke sonucundaki oranı belirlenirken dikkate alınmıştır. Bu nedenle, Batılı ve Batılı olmayan ülke rakamları ile toplam ülke sonucu rakamları eşit değildir.

\section{Araştırmanın Bulguları}

Bu çalışmada, genel olarak dünyadaki, özel olarak da Türkiye' deki mevcut popüler kültür eğilimlerinin "kültürel homojenleşme" ve "kültürel melezleşme" tezlerinden hangisine daha yakın olduğu tespit edilmeye çalışılmıştır. Bu amaçla, Google Trends sitesinde yer alan veriler kullanılarak, Evrensel kategorisinde 2001-2015 yılları arasındaki dönemle ilgili olarak yer alan 10 başlık altında toplam 753, Türkiye kategorisinde ise 2011-2015 y1lları arasındaki dönemle ilgili olarak yer alan 12 başlık altında ise 299 sorgu kodlanmıştır. Kodlama sonucunda, toplam olarak Evrensel kategorisinde 764, Türkiye kategorisinde ise 302 ülke tespit edilmiştir. Daha sonra, bu ülkeler Batılı ülke/Batılı olmayan ülke ayrımına tabi tutularak arama sorgularıyla ilişkili ülkelerin yer alma sıklıkları (n) ve yüzdeleri (\%) hesaplanmıştır. Çalışmanın çıkış noktasını oluşturan üç araştırma sorusuna bu veriler temelinde bulunan yanıtlar şu şekilde sıralanabilir:

\section{A.S.1. Kültürel küreselleşme kültürel homojenleşmeye mi yoksa melezleşmeye mi yol açmaktadır?}

Evrensel kategorisinde taranan 10 başlıkta tespit edilen Batılı ülke sonucu sayısı 591, Batılı olmayan ülke sonucu sayısı ise 114'tür. Başka bir ifadeyle, Batılı ülke sonucu sayısı, Batılı olmayan ülke sonucu sayısının 5.1 katı fazladır (bkz. Tablo 3). 
Tablo 3: Evrensel ve Türkiye Kategorilerindeki Arama Sorgularının Batılı ve Batılı Olmayan Ülke Temelinde Dağılımı

\begin{tabular}{|c|c|c|c|c|c|}
\hline Batılı Ülkeler & Evrensel & Türkiye & Batılı Olmayan Ülkeler & Evrensel & Türkiye \\
\hline$A B D$ & 440 & 19 & Afganistan & 1 & \\
\hline Almanya & 5 & 1 & Arjantin & 1 & \\
\hline Avustralya & 12 & & BAE & & 1 \\
\hline Avusturya & 1 & & Barbados & 2 & 1 \\
\hline Belçika & & 3 & Brezilya & 10 & \\
\hline Danimarka & & 1 & Çin & 1 & \\
\hline Finlandiya & 5 & & Dominik & 2 & \\
\hline Fransa & 20 & 5 & Fas & 2 & \\
\hline Galler & 1 & & Filipinler & 1 & \\
\hline Hollanda & 6 & & Filistin & & 1 \\
\hline İngiltere & 57 & 1 & G. Afrika & 5 & \\
\hline İrlanda & 3 & & G. Kore & 15 & 4 \\
\hline İskoçya & 2 & & Haiti & 2 & \\
\hline İspanya & 7 & 1 & Hindistan & 5 & \\
\hline İsveç & 3 & 1 & Irak & 3 & 1 \\
\hline İsviçre & 1 & & İran & 1 & \\
\hline İtalya & 6 & & İsrail & 1 & \\
\hline Kanada & 19 & 1 & Japonya & 10 & 1 \\
\hline Polonya & 1 & & K. Kore & 1 & \\
\hline \multirow[t]{21}{*}{ Portekiz } & 2 & & Kenya & 1 & \\
\hline & & & Kolombiya & 8 & \\
\hline & & & Kıbrıs R. K. & 1 & \\
\hline & & & KKTC & & 2 \\
\hline & & & Küba & 2 & 1 \\
\hline & & & Libya & 2 & \\
\hline & & & Maldivler & 0 & 2 \\
\hline & & & Malezya & 2 & \\
\hline & & & Meksika & 4 & 1 \\
\hline & & & Misır & & 1 \\
\hline & & & Nepal & 1 & \\
\hline & & & Pakistan & 1 & \\
\hline & & & Panama & & 1 \\
\hline & & & Rusya & 7 & \\
\hline & & & S. Arabistan & 2 & \\
\hline & & & Şili & 1 & \\
\hline & & & Singapur & & 1 \\
\hline & & & Suriye & 1 & \\
\hline & & & Tayland & & 1 \\
\hline & & & Tayvan & 6 & \\
\hline & & & Türkiye & 2 & 238 \\
\hline
\end{tabular}




\begin{tabular}{|c|c|c|c|c|c|}
\hline & & & Uganda & 1 & \\
\hline & & & Ukrayna & 1 & \\
\hline & & & Uruguay & 1 & \\
\hline & & & Vietnam & 2 & 1 \\
\hline & & & Y. Zelanda & 4 & \\
\hline & & & Yunanistan & 1 & \\
\hline Toplam & 591 & 33 & Toplam & 114 & 258 \\
\hline \multicolumn{3}{|c|}{$\begin{array}{c}\text { Batılı Ülke Sonucu (Evrensel + Türkiye) } \\
: 624\end{array}$} & \multicolumn{3}{|c|}{$\begin{array}{l}\text { Batılı Olmayan Ülke Sonucu (Evrensel + Türkiye) } \\
: 372\end{array}$} \\
\hline
\end{tabular}

Evrensel kategorisinde elde edilen ülke sonuçlarında birinci sırada ABD ( $\mathrm{n}=440 / 764$, $\% 57,5)$, ikinci sırada ise İngiltere $(\mathrm{n}=57 / 764, \% 7.4)$ yer almaktadır.

Kültürel homojenleşme sürecinin nasıl bir seyir izlediğini tespit etmek üzere Evrensel kategorisinde yer alan 15 y1llı sürenin ilk ve son y1llarında (2001 ve 2015) elde edilen veriler birbiriyle karşılaştırılmıştır. Bu iki yılın her ikisi için verilerin bulunduğu Genel Aramalar, Televizyon Programları, Kişiler, Spor, Filmler, Müzik Sanatçıları başlıkları kapsamında yapılan analiz, 15 yıllık zaman diliminde Batılı ülkeler lehine küçük de olsa $(\mathrm{p}<2)$ bir farklılaşma yaşandığını göstermiştir (bkz. Tablo 3).

Tablo 4: Evrensel kategorisinde yer alan 15 yıllık sürenin ilk ve son yllarında (2001 ve 2015) elde edilen verilerin karşılaş̧ırılması

\begin{tabular}{|c|c|c|c|c|c|c|c|}
\hline \multicolumn{4}{|c|}{2001 (Evrensel) } & \multicolumn{4}{|c|}{2015 (Evrensel) } \\
\hline \multicolumn{2}{|c|}{ Batılı Ülkeler } & \multicolumn{2}{|c|}{ Batılı OImayan Ülkeler } & \multicolumn{2}{|c|}{ Batılı Ülkeler } & \multicolumn{2}{|c|}{ Batılı Olmayan Ülkeler } \\
\hline$A B D$ & 37 & S. Arabistan & 2 & $A B D$ & 36 & Brezilya & 2 \\
\hline İngiltere & 6 & Afganistan & 1 & İngiltere & 1 & Hindistan & 3 \\
\hline Fransa & 5 & Arjantin & 1 & Avustralya & 5 & Japonya & 1 \\
\hline Avustralya & 2 & Hollanda & 1 & Fransa & 3 & & \\
\hline İrlanda & 2 & Japonya & 1 & İrlanda & 1 & & \\
\hline \multirow[t]{3}{*}{ Kanada } & 1 & Rusya & 1 & & & & \\
\hline & & Y. Zelanda & 1 & & & & \\
\hline & 53 & & 8 & & 46 & & 6 \\
\hline \multicolumn{4}{|c|}{$\begin{array}{l}\text { Toplam: } 53+8=61 \\
\text { Batılı Ülke Oranı: } 53 / 61=\% 86,88 \\
\text { Batılı Olmayan Ülke Oranı: 8/61=13.11 }\end{array}$} & \multicolumn{4}{|c|}{$\begin{array}{l}\text { Toplam: } 46+6=52 \\
\text { Batılı Ülke Oranı: } 46 / 52=\% 88.46 \\
\text { Batılı Olmayan Ülke Oranı: } 6 / 52=\% 11.53\end{array}$} \\
\hline \multicolumn{8}{|c|}{$\begin{array}{l}2001 \text { ile } 2015 \text { yılları arasındaki fark: } \\
\text { Batılı Ülke } \\
\text { Batılı Olmayan Ülke } \\
\text { : } \% 1.80 \\
-\% 1.58\end{array}$} \\
\hline
\end{tabular}

\section{A.S.2. Küresel kültür giderek Amerikan kültürüne mi benzemektedir?}

ABD'yle ilişkili arama sorgularının toplam Batılı ülke sonucuna oranı Evrensel kategorisinde yüzde $74.4(\mathrm{n}=440 / 591)$ ve Türkiye kategorisinde yüzde $57.5(\mathrm{n}=19 / 33)$ olarak tespit edilmiştir (bkz. Şekil 1). 

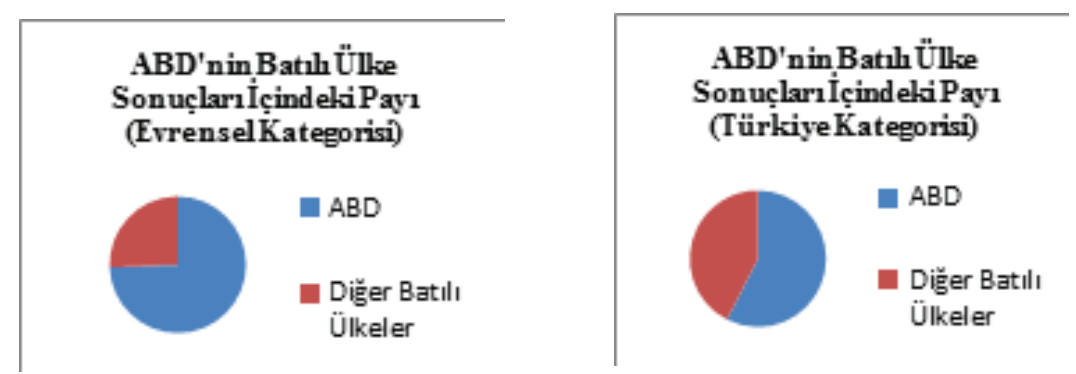

Şekil 1: ABD'yle İlgili Arama sorgularının Batıı Ülkeler İçindeki Oranı

Evrensel kategorisinde, ABD’nin en yüksek oranda yer aldığı ilk beş başlığın Filmler $(n=40 / 57, \% 70.1)$, Kaybettiklerimiz $(n=34 / 45, \% 75.5)$, Televizyon Programları $(n=46 / 65$, \%70.7), Müzik Sanatçıları ( $\mathrm{n}=21 / 30, \% 70)$ ve Eğlence $(\mathrm{n}=28 / 40, \% 70)$ olduğu tespit edilmiştir.

A.S.3. Türkiye'de hâkim kültürel eğilimler dünya genelindeki kültürel küreselleşme eğiliminden farklıllk göstermekte midir?

Türkiye kategorisinde taranan 12 başlıkta tespit edilen Batılı ülke sayısı 33, Batılı olmayan ülke sayısı ise 258'dir. Başka bir ifadeyle, Batılı olmayan ülke sayısı Batılı ülke sayısının 21.5 katı fazladır (bkz. Tablo 3).

Türkiye'yle ilişkili olduğu tespit edilen 238 arama sonucunun Batıl1-Batılı olmayan ülke sonuçlarının değerlendirilmesinde yanıltıcı etki yapmasını önlemek amacıyla, Batılı olmayan toplam ülke sonucundan $(n=372)$ Türkiye sonucu $(n=238)$ çıkarılmış, böylece yerel etkiden arındırılmış Batılı olmayan ülke sonucuna $(n=134)$ ulaşılmıştır. Yerel etkiden arındırılmış sonuçlar üzerinden yeniden değerlendirildiğinde, Türkiye kategorisinde Batılı ülke sorgularının $(n=33)$ Batılı olmayan ülke sayısından ( $n=20) 1.6$ kat fazla olduğu tespit edilmiş̧ir.

Türkiye kategorisinde elde edilen ülke sonuçlarında, birinci sırada Türkiye ( $n=238 / 302$, \%78.8), ikinci sırada ABD ( $\mathrm{n}=19 / 302, \% 6.2)$ yer almaktadır. Yine bu kategoride, beş başlıkta (Şarkıcılar, Şarkılar, Spor Takımları, Diziler ve Şöhretler) tüm sonuçların (\%100) ilişkili ülkesinin Türkiye olduğu tespit edilmiştir.

Google Trends sitesinde Türkiye kategorisindeki arama sorgularının yalnızca kısa bir dönem (2011-2015 arası) için verilmiş olması nedeniyle, bu kategoride zaman içindeki değişimi ölçmeye yönelik bir karşılaştırma yapılamamıştır.

\section{Sonuç}

$\mathrm{Bu}$ çalışmanın amac1, küreselleşme sürecinin kültürel homojenleşmeye mi yoksa melezleşmeye mi yol açtığına ilişkin tartışmalara katkıda bulunabilecek deneysel verilere ulaşmaktır. Bu doğrultuda, Google Trends sitesinde 2011-2015 y1lları arasında Evrensel kategorisinde ve 2011-2015 yılları arasında Türkiye kategorisinde yer alan arama sorguları bir içerik analizine tabi tutulmuştur. Analiz bulguları temelinde ulaşılan sonuçlar şu şekilde özetlenebilir:

a. Evrensel kategorisinde elde edilen bulgular, Batılı ülke sonucu sayısının Batılı olmayan ülke sonucu sayısından 5.1 kat fazla olduğunu göstermiştir. Bu ise, başta ABD olmak üzere Batı kültürünün dünyanın internet erişimine sahip nüfusu üzerinde önemli bir etkisinin bulunduğunu göstermekte ve küreselleşmenin kültürel homojenleşmeye yol açtığı tezini desteklemektedir.

b. Kültürel homojenleşme sürecinin nasıl bir seyir izlediğini tespit etmek üzere Evrensel kategorisinde yer alan 15 yıllık sürenin ilk ve son y1llarında (2001 ve 2015) elde edilen verilerin birbiriyle karşılaştırılması sonucunda, örneklemin kapsadığı süre içinde Batılı 
ülkeler lehine küçük de olsa $(\mathrm{p}=1.80)$ bir farklılaşma yaşandığını tespit edilmiştir. Küreselleşme süreci Anthony Giddens (1990) gibi modernleşme sürecinin bir sonucu olarak görülür ve özellikle medya sektöründeki küreselleşmede yaşanan hızlanmanın geçmişinin 50 yılı aşmamış olduğu dikkate alınırsa, 15 yıllık bir sürede Batılı ülkeler lehine yaşanan yüzde 1.80 oranındaki farklılaşmanın anlamlı olduğu söylenebilir.

c. Araştırmada elde edilen ülke sonuçları içinde ABD'nin büyük bir ağırlıkla yer aldığı görülmektedir. Öyle ki, ABD'yle ilişkili arama sorgularının toplam Batılı ülke sonucuna oranı Evrensel kategorisinde yüzde $74.4(n=440 / 591)$ ve Türkiye kategorisinde yüzde 57.5 $(\mathrm{n}=19 / 33)$ olarak tespit edilmiştir. ABD'nin ağırlı̆̆ 1 özellikle Filmler (\%70.1), Televizyon Programları (\%70.7), Eğlence (\%70), Müzik Sanatçıları (\%70) ve Kaybettiklerimiz (\%75.5) başlıklarında kendini göstermiştir. Bu ise, kitlelerin eğlence dünyasına yönelik kültürel ilgilerinin ağırlıklı olarak ABD'nin etkisinde olduğunu düşündürmektedir.

d. Türkiye kategorisinde elde edilen veriler Batılı olmayan ülke sayısının Batılı ülke sayısından çok daha fazla (21.5 katı) olduğunu göstermişse de, yerel kültürel öğelerin varlığından dolayı bu verilerin olduğu haliyle dikkate alınması yanıltıcı olacaktır. Bu nedenle, Türkiye'yle ilişkili olduğu tespit edilen arama sonuçları $(\mathrm{n}=238)$ Batılı olmayan toplam ülke sonuçlarından $(\mathrm{n}=372)$ çıkarılarak yerel etkiden arındırılmış sonuçlara ulaşılmıştır. Ortaya çıkan tablo, Batı1ı ülkelerle ilişkili sorguların ( $\mathrm{n}=33$ ) Batılı olmayan ülkelerle ilişkili sorgulardan $(\mathrm{n}=20) 1.6 \mathrm{~kat}$ fazla olduğu şeklindedir. Batılı ülkelerle ilişkili toplam 33 sorgunun 19'unun ABD'ye ait olması da dikkate alındığında, Türkiye'de hâkim kültürel öğelerin küresel düzeydeki popüler kültür eğilimleriyle uyumlu olarak başta $\mathrm{ABD}$ olmak üzere Batılı ülkelerin hâkimiyeti altında olduğu söylenebilir.

$\mathrm{Bu}$ çalışma, kapsadığı verilerin tutarlılık göstermemesinden doğan sinırlılıklarına rağmen, Google Trends sitesinin toplumların kültürel ilgi alanlarının tespiti açısından faydalı bir araç olduğunu ortaya çıkarmıştır. Ancak, yazarların araştırma olanaklarının yalnızca Türkçe ve İngilizce dilleriyle sınırlı olmasından dolayı, Google Trends sitesinde ülke temelinde yapılan kodlamada yalnızca Türkiye dikkate alınmış, diğer ülkeler göz ardı edilmiştir. Bu sınırlı1ık, diğer ülkelere ilişkin veriler üzerinde benzer araştırma soruları temelinde yapılacak araştırmalarla tamamlanabilir.

Çalışmanın bir diğer sınırlılığı, Google'daki sorgulamanın dünyanın internet kullanan nüfusun eğilimlerini yansitıyor olmasıdır. İnternet erişimi olmayan veya yetersiz erişime sahip kesimlerin kültürel eğilimlerini tespit etmek için farklı araştırma yöntemleri üzerinden araştırma yapılması ve sonuçların bu araştırmanın sonuçlarıyla karşılaştırılması faydalı olacaktır. 


\section{KAYNAKÇA}

Bragazzi, N. L. (2014) Googling Insects as a New Trend in Cultural Entomology: An Italian Perspective. The Open Entomology Journal, 8, 17-21. Erişim: 15 Mayıs 2016, Benthamopen.

Bruce, S. \& Yearley, S. (2006). The Sage Dictionary of Sociology [Elektronik Sürüm]. London: Sage Publications.

Burton, G. (2005). Media and Society: Critical Perspectives [Elektronik Sürüm]. New York: Open University Press.

Carlsson, U. (2002). Foreward. C. Von Felitzen\&U. Carlsson (Ed.). Children, Young People and Media Globalisation (7-11) [Elektronik Sürüm]. Goteborg, Sweden: UNESCO International Clearinghouse on Youth and Media.

De Block, L. \& Buckingham, D. (2007). Global Children, Global Media: Migration, Media and Childhood [Elektronik Sürüm]. New York: Palgrave Macmillan.

Fiske, J. (1991). Popüler Kültürü Anlamak (S. Irvan, Çev.). Ankara: Bilim ve Sanat Yayınları.

Giddens, A (1990). The Consequences of Modernity [Elektronik Sürüm]. Cambridge: Polity Press.

Gökalp, E. (2009). Kültür ve Toplum. N. Suğur, (Ed.). Sosyolojiye Giriş (98-124) [Elektronik Sürüm]. Eskişehir: Anadolu Üniversitesi, Açıköğretim Yayınları.

Hall, S. (1991). The Local and the Global: Globalization and Ethnicity. A. D. King (Ed.). Culture, Globalization and the World System (19-39) [Elektronik Sürüm]. New York: Macmillan.

Heywood, A. (2011). Global Politics (2nd Ed.) [Elektronik Sürüm]. New York: Palgrave.

Hjarvard, S. (1999). Global Media Cultures: A Research Programme on the Role of Media in Cultural Globalization. Nordicom Review, 20(2), 71-78. Erişim: 14 Mayıs 2016, Nordicom.

Huntington, S. P. (1996). The Clash of Civilizations and the Remaking of World Order [Elektronik Sürüm]. New York: Simon\&Shuster.

Jung, S. \& Li, H. (2014). Global Production, Circulation, and Consumption of Gangnam Style. International Journal of Communication [Online], 8, 2790-2810. Erişim: 15 Mayıs 2016, IJOC.

Kellner, D. \& Pierce, C. (2007). Media and Globalization. Ritzer, G. (Ed.). The Blackwell Companion to Globalization (383-395) [Elektronik Sürüm]. Malden: Blackwell Publishing.

Kendall, D. (2011). Sociology In Our Times, The Essentials (8th Ed.) [Elektronik Sürüm]. Belmont, CA: Wadsworth/Thompson Learning.

Krippendorff, K. (2004). Content Analysis: An Introduction to Its Methodology (2nd ed.). California: Sage.

MacDonald, D. (1963). A Theory of Mass Culture. B. Rosenberg \& D. White (Eds.). Mass Culture: The Popular Arts in America (59-73) [Elektronik Sürüm]. New York: The Free Press of Glencoe. 
Markey, P. M., Markey, C. N., \& French, J. E. (2014). Violent Video Games and Real-World Violence: Rhetoric Versus Data. Psychology of Popular Media Culture. Erişim: 10 Mayis 2016, https://nature.berkeley.edu/garbelottoat/wp-content/uploads/markyetal-2014.pdf

Marshall, G. (2005). Sosyoloji Sözlüğ̈̈ (2. bs) [Elektronik Sürüm]. (O. Akınhay ve D. Kömürcü, Çev.). Ankara: Bilim ve Sanat Yayınları.

Matos, C. (2012). Globalization and the Mass Media. G. Ritzer (Ed.) Encyclopedia of Globalization [Elektronik Sürüm]. Oxford: Wiley-Blackwell.

Ritzer, G. (2011). Globalization: The Essentials [Elektronik Sürüm]. Oxford: Wiley Blackwell.

Robertson, R. (1998). Globalization: Social Theory and Global Culture Theory, Culture \& Society [Elektronik Sürüm]. London: Sage Publications.

Smith, P. (2001). Cultural Theory: An Introduction [Elektronik Sürüm]. Malden: Blackwell Publishing.

Storey, J. (2009). Cultural Theory and Popular Culture: An Introduction (5th ed.) [Elektronik Sürüm]. New York: Pearson Longman.

Strinati, D. (2004) An Introduction to Theories of Popular Culture (2nd ed.) [Elektronik Sürüm]. London: Routledge.

Takada, K. (2011). Popularity of different lampyrid species in Japanese culture as measured by Google search volume. Insects, 2, 336-342. Erişim: 10 Mayıs 2016, Insects.

Williams, R. (1983). Keywords: A Vocabulary of Culture and Society [Elektronik Sürüm]. New York: Oxford University Press.

Yaylagül, L. \& Korkmaz, N. (2008). Kitle Kültürü/Popüler Kültür Tartışmaları. L. Yaylagül ve N. Korkmaz (Ed.). Medya, Popüler Kültür ve İdeoloji (125-138). Ankara: Dipnot Yayınlar1.

Yıldırım, A. ve Şimşek, H. (2008). Sosyal Bilimlerde Nitel Araştırma Yöntemleri. Ankara: Seçkin. 